\title{
Genetic Determinism in Community Staphylococcus and Methicillin-Resistant Clinics in Brazzaville, Republic of Congo
}

\author{
AHOMBO Gabriel ${ }^{1}$, MOYEN Rachel ${ }^{1}$, BALOKI NGOULOU Tarcisse ${ }^{1}$, KAYATH Aimé \\ Christian $^{1,2}$, ONTSIRA NGOYI Nina Esther ${ }^{3}$ \\ ${ }^{1}$ Molecular and Cellular Biology Laboratory, Technical and Sciences Faculty, Marien Ngouabi University, \\ Brazzaville, Congo \\ ${ }^{2}$ Exact and Natural Science Research Institute, Brazzaville Congo \\ ${ }^{3}$ Bacteriology-Virology Laboratory, University Hospital Center, Health Sciences Faculty, Marien Ngouabi University, \\ Brazzaville, Congo
}

Corresponding author: AHOMBO Gabriel; gabriel.ahombo@umng.cg

Received 01 July 2019;

Accepted 21 July 2019;

Published 26 July 2019

\begin{abstract}
In order to demonstrate the transmission of resistance genes between clinical bacteria and community bacteria, 78 strains of Staphylococcus including $56(71.79 \%)$ community strains and $22(28.21 \%)$ clinical strains were isolated and identified according to classical methods of microbiology. The resistance pattern was determined by the standard Mueller Hinton diffusion method. The phenotype of methicillin-resistant Staphylococci was investigated from the oxacillin disc and cefoxitin. PCRs were performed on 45 DNA strains of Staphylococcus including 25 $(55.56 \%)$ of community strains and $20(44.44 \%)$ of clinical strains resistant to oxacillin and cefoxitin alone or associated. Phenotypic results indicate that norfloxacin, ciprofloxacin, tobramycin, kanamycine were more active on community Staphylococci. In clinical Staphylococcus, only tobramycin was more active. The differences were significant between the resistance frequencies of community and clinical Staphylococci for some antibiotics with a P value $<0.05$. The mec A gene was identified in 9 community S.aureus strains, 6 clinical strains of Staphylococcus . The fragments of the amplified gene were of the same molecular weight $(500 \mathrm{bp})$, which suggests a spread of clinical strains in the city.
\end{abstract}

Keywords: Determinism, genetic, Staphylococcus, methicillin.

\section{Introduction}

Staphylococcal infections are observed in multiple clinical situations, both in community pathology and nosocomial pathology. Staphylococcus aureus is considered to be an important cause of a wide variety of diseases in humans, such as: food poisoning, pneumonia, wounds and nosocomial infections ${ }^{[1],[2]}$. There are many anti-staphylococcal agents; however, the bacterium has developed mechanisms to neutralize them such as the mechanism of resistance to méthicilline ${ }^{[3]}$. Methicillin-resistant Staphylococcus aureus (MRSA) is a cause of healthcare-associated infections $^{[1]}$, the community ${ }^{[2]}$ and associated with livestock worldwide $^{[4]}$. The treatment of infections has become increasingly difficult due to the high prevalence of methicillin-resistant strains and the development of the emergence of multidrug-resistant strains in different families of antibiotics. This phenomenon is observed at the hospital but also in the city ${ }^{[5]}$. MRSA (methicillinoresistance) infections exacerbate the prognosis and severely complicate the management of staphylococcal infections, which is a major public health problem ${ }^{[6],[7]}$. In the United States, about 29\% (78.9 million people) and $1.5 \%$ (4.1 million) of the population have $S$. aureus and MRSA, respectively city ${ }^{[8]}$. An estimated 478,000 hospitalizations were associated with $S$. aureus infections, including 278,000 hospitalizations in $2005^{[9]}$. This situation led us to study the current state of this microorganism in Congo Brazzaville. Given that, little work has been done on this microorganism $^{[10],[11]}$. Thus, this work aims to study the genetic determinism of resistance in Staphylococcus between community and clinical strains. By doing a comparative study of the resistance profiles as well as a PCR amplification of the mec A gene.

\section{Material and Methods}

1. Equipment

The biological material consisted of community strains isolated from household wastewater, biological products from outpatients 
and isolated clinical strains from patients hospitalized at the Brazzaville University Hospital Center (CHUB).

\section{Methods}

\subsection{Isolation and identification of strains}

Isolated strains of wastewater were isolated from Chapman agar between July and September 2017. In outpatients the strains were isolated between January and March 2018 at the COGEMO clinic in Brazzaville. The clinical strains were isolated between January and July 2017 in the different departments of CHUB. The identification of community strains was made on the basis of culture traits on Chapman agar and biochemical (coagulase test) and by the API Staph gallery for clinical strains.

\subsection{Antibiotic resistance}

The resistance profile of bacterial strains has been evaluated by the standard antibiogram using the Mueller Hinton medium diffusion method $^{[12],[13]}$. The antibiotics tested were the following: penicillin G (P., 10UI), oxacillin (OXA., 1 $\mu \mathrm{g}$ ), cefoxitin (CX., 30 $\mu \mathrm{g}$ ), vancomycin (VA., 30 $\mu$ g), Kanamycin (K., 5UI), gentamicin (CN.,

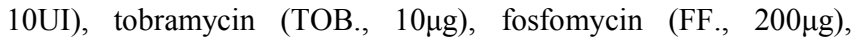
ciprofloxacin (CIP., $5 \mu \mathrm{g}$ ), norfloxacin (NOR., 10 $\mu \mathrm{g}$ ), erythromycin (E., 15 $\mu \mathrm{g}$ ), clindamycin (DA.,2 $\mu \mathrm{g}$ ), pristinamycin (PT., $15 \mu \mathrm{g}$ ), fusidic acid (FA., $10 \mu \mathrm{g}$ ), rifampicin (RA., $5 \mu \mathrm{g}$ ). The antibiotic discs were applied to Mueller Hinton medium seeded by plating an inoculum prepared from a pure, young Staphylococcus colony. Antibiotic susceptibility was determined by the standard susceptibility testing method on Mueller Hinton medium. The resistance of Staphylococci to methicillin is investigated using oxacillin disks (OXA., $1 \mu \mathrm{g}$ ) in hypersaline Mueller Hinton medium $(4 \% \mathrm{NaCl})^{[36]}$ and cefoxitin $(\mathrm{CX}$., $30 \mu \mathrm{g})$. After 18 to 24 hours of incubation in an oven at $37^{\circ} \mathrm{C}$., the diffusion diameters of the various antibiotics were measured and compared with the reference diameters of the antibiogram committee of the French Microbiology Society ${ }^{[14]}$.

\subsection{Molecular detection of the mecA gene \\ 1. DNA extraction}

A total of 45 DNAs of Staphylococcus strains with a resistance phenotype of oxacillin and cefoxitin alone or associated were extracted by the nucleoSpin DNA Kit according to the MACHEREY NAGEL protocol.

\section{Realization of the PCR}

A PCR reaction was performed for amplification of the $310 \mathrm{bp}$ fragment of the mecA gene using the primers; mec A-F: 5'AAAATCGATGGTAAAGGTTGGC-3 'and mec A: 5'AGTTCTGCAGTACCGGATTTGC- $3^{[15],[16]}$. The PCR amplification reaction mixture $(50 \mu \mathrm{l})$ contained $2 \mu \mathrm{l}$ of DNA template and $48 \mu \mathrm{l}$ of the mix. The mix consisted of $31.75 \mu \mathrm{l}$ of sterile distilled water, $2 \mu \mathrm{l}$ of F primer, $2 \mu \mathrm{l}$ of R primer, $2 \mu \mathrm{l}$ of dNTPs, $10 \mu$ of PCR buffer (x5) and $0.25 \mu$ of one taq. The PCR amplification conditions were as follows: initial denaturation at $94^{\circ} \mathrm{C}$ for $5 \mathrm{~min}, 30$ denaturation cycles at $94^{\circ} \mathrm{C}$ for $30 \mathrm{sec}$, hybridization at $54^{\circ} \mathrm{C}$ for $30 \mathrm{sec}$, elongation at $72^{\circ} \mathrm{C}$ for $30 \mathrm{sec}$ and final elongation at $72^{\circ} \mathrm{C}$ for 7 minutes.

\section{Agarose gel electrophoresis of PCR products of the mec A gene}

Five microliters $(5 \mu \mathrm{l})$ of PCR product were resolved on a $1.5 \%$ agarose gel containing $0.5 \mu \mathrm{g} / \mathrm{ml}$ of ethidium bromide in TrisBorate-EDTA buffer at $100 \mathrm{~V}$ for 40 minutes.

\subsection{Data processing}

For the analysis of resistance data, intermediate category strains were counted as resistant $(I+R)$. The data were analyzed using Graph Pad Prism 7 software. The Chi square test $\left(\mathrm{X}^{2}\right)$ was used to compare the resistance frequencies of community and clinical Staphylococcus strains. The $95 \%$ confidence interval and one degree of freedom of 1 were used. The difference between the frequencies was considered significant when the $\mathrm{p}$ value was less than 0.05 .

\section{Results}

\subsection{Isolation and identification of strains}

In this study, 78 strains of Staphylococcus were isolated from household wastewater samples, biological products from outpatients and inpatients. Of these strains, 56 (71.79\%) were community strains and $22(28.21 \%)$ were clinical strains. Among community strains, we identified $49(87.5 \%)$ strains of S.aureus and $7(12.5 \%)$ strains of coagulase-negative Staphylococcus (SCN). The 22 clinical Staphylococcus strains consisted of 11 (50\%) S.aureus strains and $11(50 \%)$ SCN strains (Figure 1).

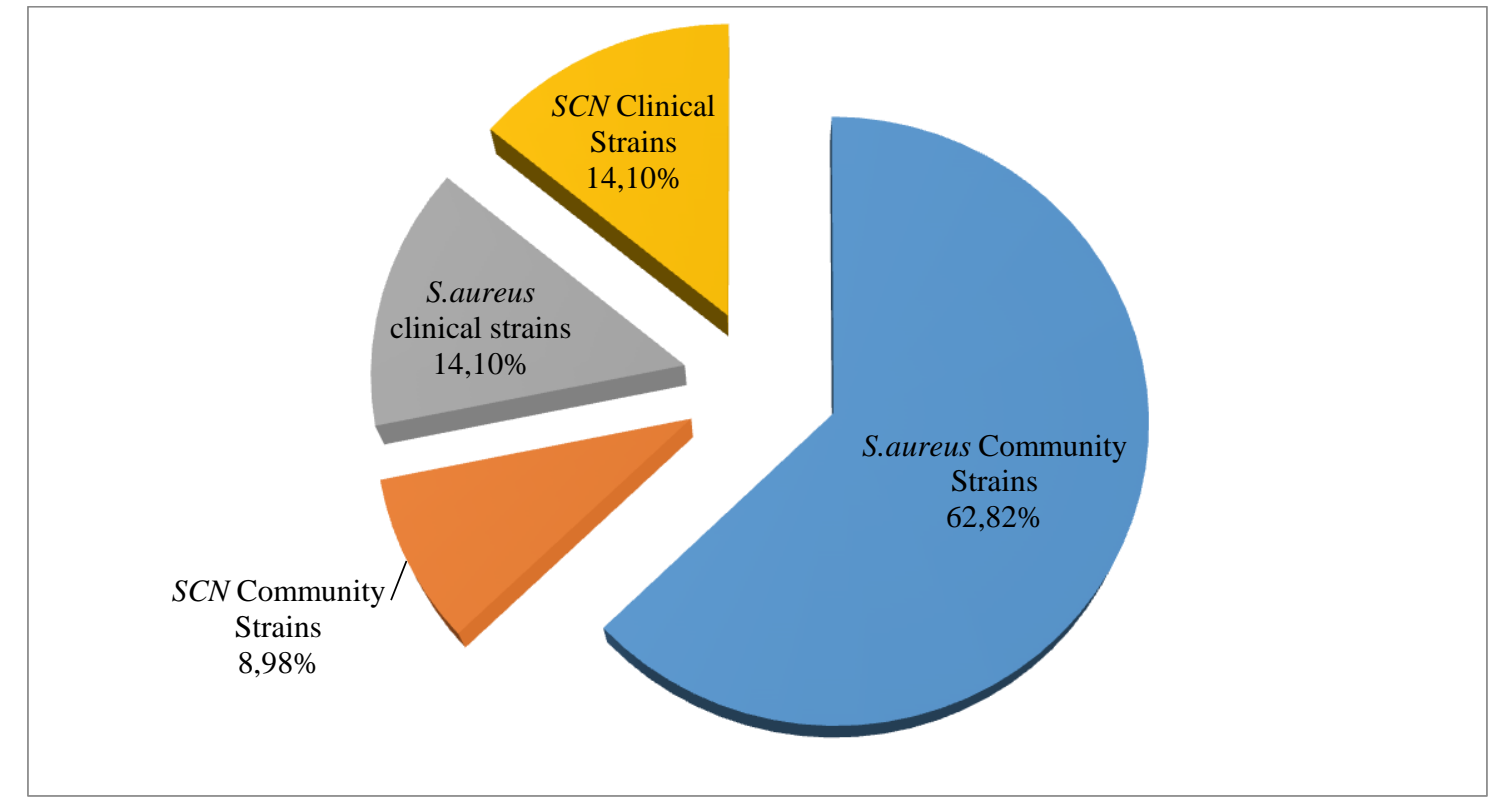

Figure 1: Distribution of Staphylococcus Strains 


\subsection{Phenotypic results}

Figure 2 shows the different levels of resistance in community S.aureus and clinical S. aureus. Forty nine (49) S. aureus strains and eleven (11) clinical $S$. aureus strains were tested. In community $S$. aureus, the highest resistance was observed with fusidic acid $(81.63 \%)$. Clinical $S$. aureus showed resistance ranging from $27.27 \%$ for tobramycin to $100 \%$ for oxacillin. The statistical test was significant for $7(46.67 \%)$ antibiotics with a P value $<0.05$. In community $S$. aureus, the OXAS CXR phenotype (oxacillin susceptibility and cefoxitin resistance) was most strongly represented. The POXACX beta-lactam resistance phenotype (resistance to penicillin G, oxacillin and cefoxitin) was more represented in clinical $S$. aureus. In macrolide-lincosamideStreptogramin (MLS) the EDAPT phenotype (resistance to erythromycin, clindamycin and pristinamycin) was more prevalent in community and clinical S. aureus.

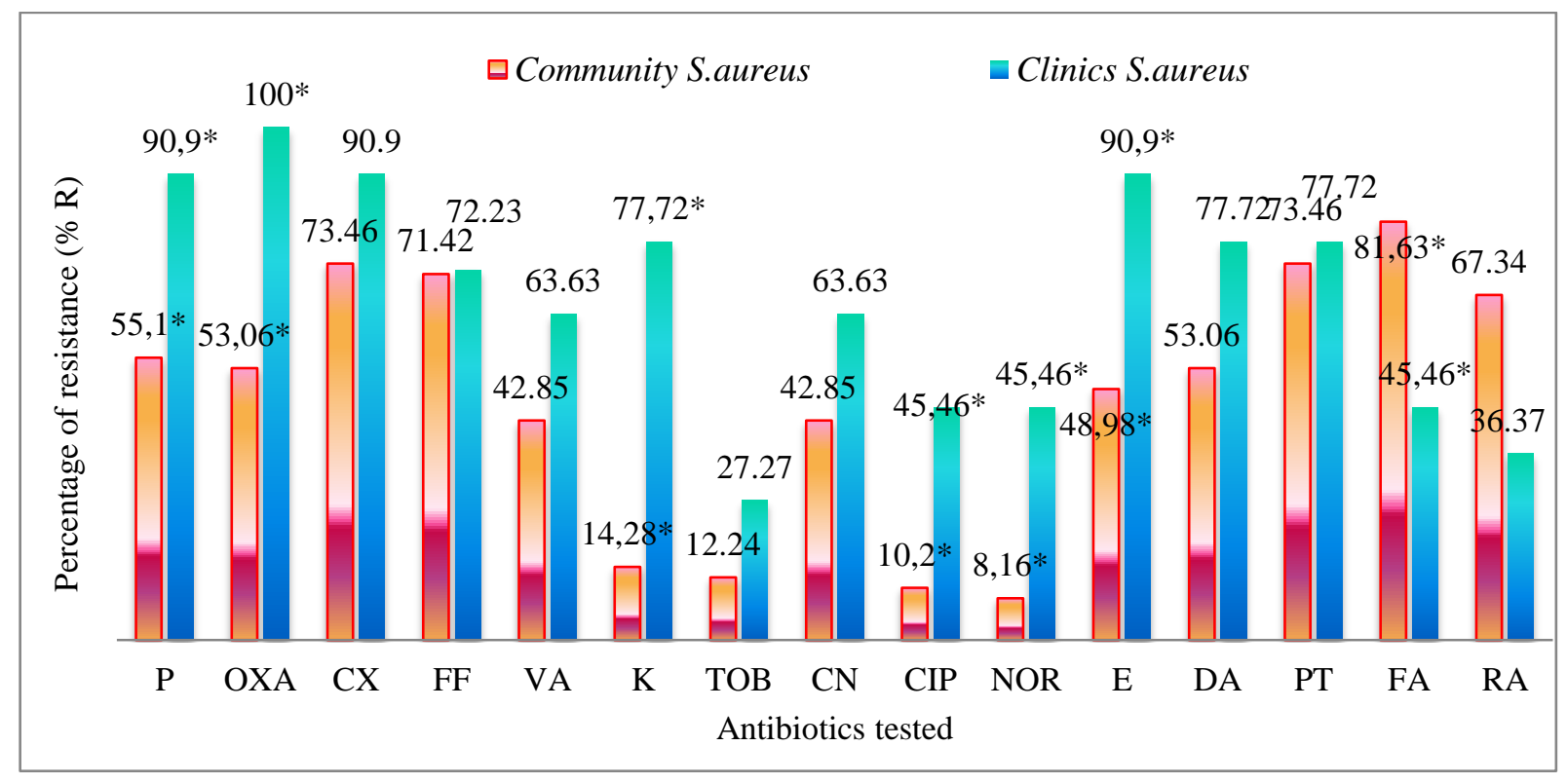

$* p<0.05$

Figure 2: Resistance profile of community $S$. aureus and clinical $S$. aureus with antibiotics tested

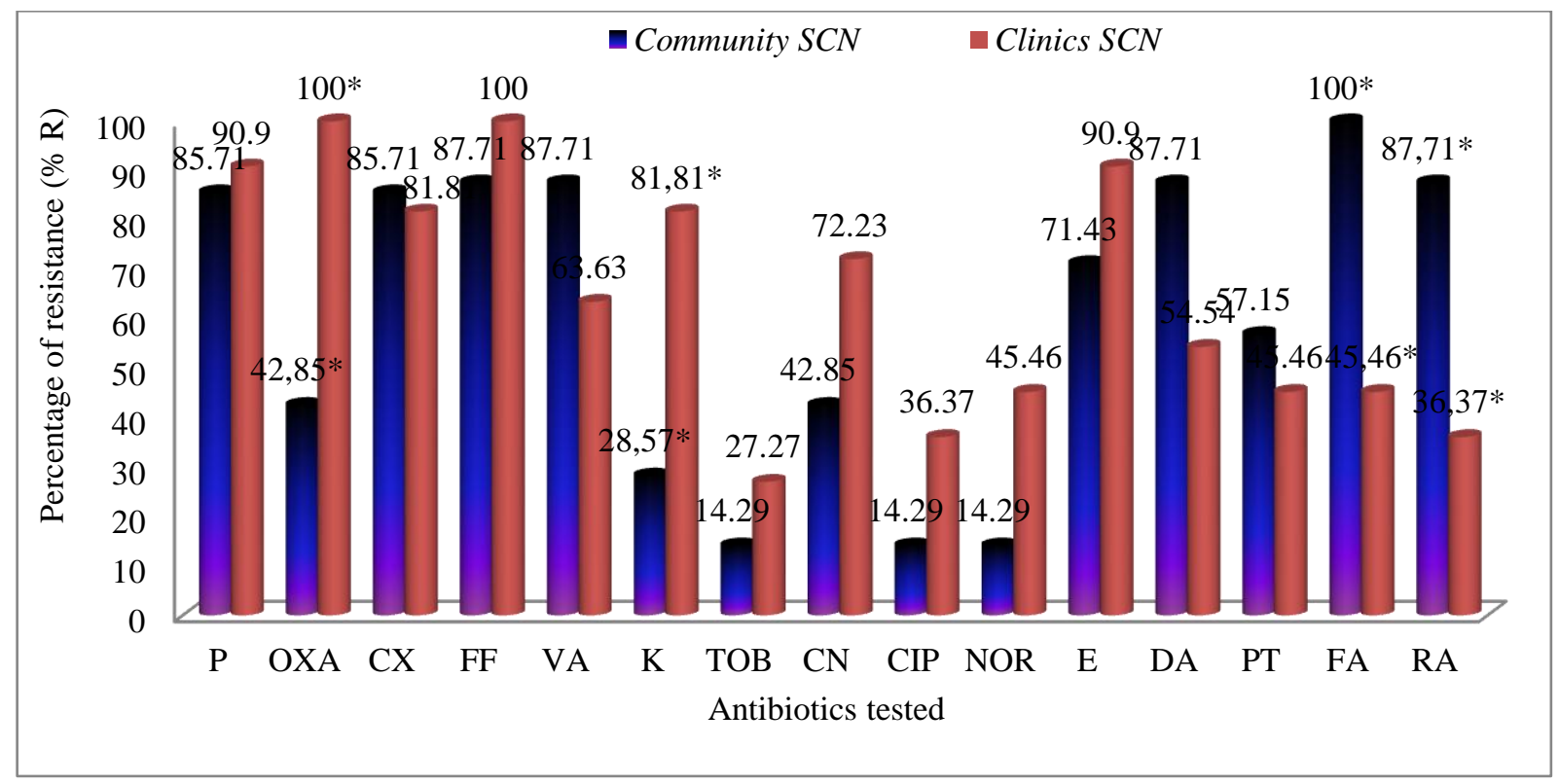

$* p<0.05$

Figure 3: Resistance profile of community and clinical SCNs with tested antibiotics

Figure 3 represents the resistance profile of community and clinical SCNs. In community SCN, tobramycin, kanamycin, ciprofloxacin and norfloxacin were more active with respective percentages of resistance: $14.29 \% ; 28.57 \%$ and $14.29 \%$.

In clinical SCN, tobramycin was the only antibiotic with good activity at $27.27 \%$. Resistance rates of $100 \%$ were observed for oxacillin and fosfomycin. The statistical test was significant for 4 (26.67\%) antibiotics including oxacillin, kanamycin, fusidic acid and rifampicin with $\mathrm{P}$ value $<0.05$. The predominant beta-lactam resistance phenotypes were: P OXA CX (resistance to penicillin G, oxacillin and cefoxitin), PROXAR (resistance to penicillin $\mathrm{G}$ and oxacillin) in community SCN and P OXA CX at SCN Clinics. For aminoglycosides, the $\mathrm{K}$ TOB $\mathrm{CN}$ phenotype (resistance to kanamycin, tobramycin, and gentamycin) was predominant in community $\mathrm{SCN}$ and $\mathrm{KCN}$ (resistance to kanamycin and gentamycin) in clinical SCNs. In macrolides-lincosamides and streptogramins, the most prominent phenotypes were EDAPT (resistance to erythromycin, clindamycin and pristinamycin) and EDA (resistance to erythromycin and clindamycin) in community and clinical SCNs. 


\subsection{Genotypic results}

The molecular study was performed on 45 DNA strains of Staphylococcus. These consist of 25 (55.56\%) DNA from community strains and $20(44.44 \%)$ DNA from clinical strains. The DNA of the community strains were composed of 19 (76\%) $S$. aureus DNA and 6 (24\%) DNA of SCN strains. The 20 DNA of the clinical strains were extracted from 11 (55\%) S.aureus and 9
(45\%) SCN. The mec A gene was identified in $9(47.36 \%)$ community S.aureus strains (Figure 4) and strain 11 in Figure 5. Four $(36.36 \%)$ clinical S.aureus strains and $2(22,22 \%)$ Clinical SCN strains (Strains 18 and 22) illustrated in Figure 5 carry the mec A gene. The chi-square test was non-significant between the community and clinical Staphylococcus strains carrying the mecA gene. The fragments of the amplified gene were $500 \mathrm{bp}$.

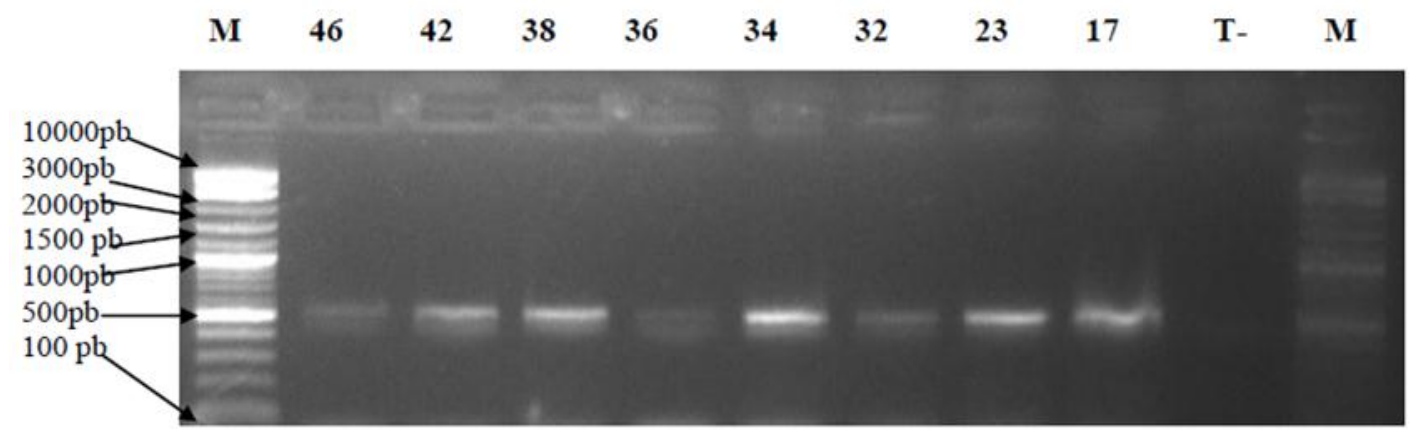

Figure 4: 1.5\% Agarose gel electrophoresis of PCR amplicon of the mec A gene obtained with the DNA of $S$. aureus strains in the community; $M=D N A$ lab marker; $T$ = negative control; 17, 23, 32, 34, 36, 38, 42 and 46: fragments of community $S$.aureus strains.

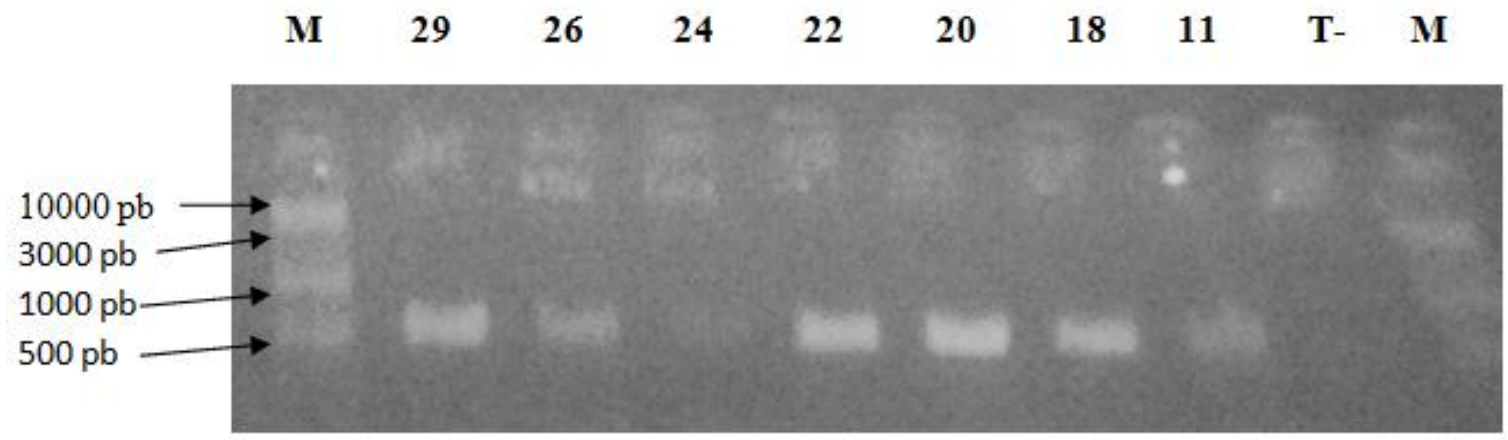

Figure 5: 1.5\% Agarose gel electrophoresis of PCR amplicon of the mec A gene obtained with the DNA of S.aureus community strains, S.aureus and SCN clinics. $M$ = DNA lab marker; $T$ = negative control; 11: fragments of community $S$.aureus strains; 18, 22: fragments of clinical SCN strains and 20, 24, 26 and 29: fragments of clinical S.aureus strains.

\section{Discussion}

The study of the spread of drug resistance genes in Staphylococci is important to control its spread ${ }^{[21],[17]}$. The results of the resistance of community $S$. aureus obtained in our study reveal variable rates from one molecule to another. Resistance rates for penicillin $\mathrm{G}$ $55.10 \%$ (27), oxacillin $53.06 \%$ (26), kanamycin $14.26 \%$ (7), tobramycin $12.24 \%$ (6), gentamicin $42,55 \%$ (21) differ from those found by ${ }^{[11]}$ in S.aureus isolated at Brazzaville University Hospital, whose respective percentages are: 100\% (42), 92.86\% (39), 97, $60 \%$ (41), $80.96 \%$ (34), $61.91 \%$ (26). Our clinical S.aureus results for the same antibiotics are: $90.90 \%(10), 100 \%(11), 77.72 \%(8)$, $27.27 \%$ (3) and $63.63 \%$ (7). These results corroborate those found by ${ }^{[11]}$ Our resistance rates for penicillin G $90.90 \%$ (10), oxacillin $100 \%$ (11), kanamycin $81.81 \%$ (9), tobramycin $27.27 \%$ (3), gentamycin $72.23 \%(8)$ at SCN clinics are quite close to those found by ${ }^{[11]}$ whose respective percentages are: $100 \%$ (10), $10 \%$ (1), $90 \%$ (9), 60\% (6), 30\% (3). About $90 \%$ of Staphylococcus spp. Strains are currently resistant to penicillin $G$ and penicillin A in France by penicillinase production ${ }^{[18]}$. The resistance of Staphylococci to penicillins $\mathrm{M}$ is secondary to a modification of the target, namely the synthesis of a penicillin binding protein PLP2a (or PLP2'), encoded by the mecA gene, and which has a decreased affinity for all beta-lactams ${ }^{[19]}$. Beta-lactam resistance in clinical S.aureus and SCN was predominantly dominated by the resistance phenotype P OXA CX. The resistance of $S$. aureus to penicillins $\mathrm{M}$ (oxacillin) is often associated with that of tobramycin and kanamycin. However, such strains generally remain susceptible to gentamicin ${ }^{[20]}$. This situation prevailed in our study where the $\mathrm{K}$ TOB $\mathrm{CN}$ phenotype was rarely encountered in 3 (15\%) S. aureus strains and $1(25 \%)$ community SCN. This phenotype has been absent in clinical Staphylococcus. Our phenotypic frequencies in community S.aureus and SCN differ from those found by ${ }^{[22]}$. Elsewhere, rates of $10 \%$ to $77 \%$ have been reported by ${ }^{[23],[24]}$. The main mechanism of resistance of Staphylococcus spp to aminoglycosides is enzymatic. The enzymes APH (3'), ANT (4') and APH (2') - AAC (6') respectively inactivate kanamycin (K phenotype), kanamycin and tobramycin (KTOB phenotype), and kanamycin, tobramycin and gentamicin (phenotype KTOBCN) ${ }^{[25]}$. Several genes for MLS resistance have been described in $S$. aureus. In France, the most frequent are ErmA, ErmB and ErmC ${ }^{[25]}$. Resistance to macrolidestreptogramins and lincosamides may also be due to msrA, a gene encoding a macrolide efflux protein ${ }^{[26]}$. The significant differences observed for penicillin, oxacillin, kanamycin, ciprofloxacin, norfloxacin, erythromycin, fusidic acid and rifampicin between community and clinical Staphylococci can be explained by the misuse of these molecules in a hospital setting. Molecular research of the mecA gene conducted during this study was performed on $25(55.56 \%)$ DNA from community strains and 20 (44.44\%) DNA from clinical strains. Nine (47.36\%) community S.aureus strains, 4 $(36.36 \%)$ clinical S. aureus strains and $2(22.22 \%)$ clinical SCN strains carried the mec A gene. Methicillin from community and clinical strains was partially bound by an additional penicillin 
binding protein (PLP2a). During our study, 3 strains of community Staphylococcus out of 25 strains resistant to oxacillin alone were selected. Two of them carried the mec gene A. Nine community strains were resistant to cefoxitin alone, $2(22.22 \%)$ of them carried the mec A gene. All other community and clinical strains were both with oxacillin and cefoxitin. In a recent study, it was shown that a high frequency of Staphylococcus isolated from biomaterials contains the mec A gene ${ }^{[27]}$. In addition, we found 2 oxacillinsensitive strains carrying the mec A gene. This result corroborates with those found by ${ }^{[28]}$. This is in contradiction with the results of ${ }^{[29]}$; they showed a complete agreement between the presence and absence of the mec A gene and the interpretation of the oxacillin disc susceptibility test. De Guisti et al. ${ }^{[30]}$ suggested that A negative mock strains currently expressed phenotypic resistance to oxacillin mediated by a mechanism other than the presence of the mec A gene. Methicillin-resistant $S$. aureus are resistant to wide range of antimicrobial agents, including MLS, fluoroquinolones, tetracyclines, aminoglycosides and chloramphenicol ${ }^{[31]}$. This is in agreement with our results in which all the community strains carrying the mec A gene were resistant to MLS by presenting the E DA PT phenotype. Methicillin resistance mediated by the mec A gene as shown by ${ }^{[15],[16],[28]}$ is consistent with our results. The mec A positive clinical strains exhibited the P OXA CX resistance phenotype to beta-lactams. This phenotype has been associated with the phenotypes E DA PT and E DA (resistance to erythromycin and clindamycin) to MLS. $42.85 \%$ of mecA positive clinical MRSA isolates presented the EDAPT resistance phenotype. This is greater than $6.09 \%$, frequency reported by ${ }^{[16]}$. This frequency is lower than that reported by ${ }^{[32]}$. Several studies have been conducted on the molecular detection of the mec A gene in Staphylococcus. Our results are similar to those reported by several studies looking for the gene A gene in Staphylococcus but differ in the size of the genes obtained (500bp in our study). This size differs from that found by ${ }^{[15],[16]}$ (310bp). This suggests that the amplified mec A gene in our study has several mutations. The presence of the mec A gene of the same molecular weight (500bp) in community S.aureus, S.aureus and clinical SCN underscores the extension of resistance genes within bacterial species from hospital to city. This is consistent with numerous resistance studies that have focused on MRSA as a nosocomial pathogen [33],[34],[28]. Layton et al. ${ }^{[35]}$, Zmantar et al. ${ }^{[37]}$ found that 28 to $41 \%$ of MRSA strains recovered from adult patients were of community origin.

\section{Conclusion}

Our study allows us to conclude that community and clinical Staphylococcus strains showed significant differences between the frequencies of resistance to a number of antibiotics. Norfloxacin, ciprofloxacin, tobramycin, kanamycin were more active on community Staphylococci. Tobramycin was more active in clinical Staphylococcus. The mec A gene was present in community S.aureus, clinical SCN and clinical S. aureus strains. The amplified gene fragments were of the same molecular weight. It is likely that he has a dissemination of clinical strains in the city as well as resistance genes. All strains carrying the mec A gene were resistant to macrolides alone and / or related. The risk of dissemination and therapeutic impasse linked to these generally multidrug-resistant strains requires the adoption of control measures to reduce and prevent their emergence. The measures to be implemented include the correct use of antibiotics, strict compliance with hygiene rules, the geographical and technical isolation of patients, epidemiological surveillance and policies to fight nosocomial infections.
A data availability statement is compulsory for research articles and clinical trials. Here, authors must describe how readers can access the data underlying the findings of the study, giving links to online repositories and providing deposition codes where applicable.

\section{Conflicts of Interest}

"The author(s) declare(s) that there is no conflict of interest regarding the publication of this paper."

\section{Funding Statement}

The research and the publication of this article were financed by authors' own funds.

\section{Acknowledgments}

We would like to thank the COGEMO clinic in Brazzaville for providing us with certain strains

\section{References}

[1] E.W. Tiemersma., L.A.M. Stef Bronzwaer, O. Lyytikäinen, J.E. Degener., P. Schrijnemakers, B. Nienke, J. Monen, W. Wolfgang, G. Hajo, Methicillinresistant Staphylococcus aureus in Europe, 1999-2002, Emerg. Infect. Dis., (10),pp. 1627-1634, 2004.

[2] A.D Kennedy, M. Otto, K.R. Braughton, A.R .Whitney, L .Chen, B. Mathema, J.R. Mediavilla, K.A. Byrne, Parkins L.D, F.C. Tenover, B.N. Kreiswirth, J.M. Musser, F.R. De Leo, Epidemic community-associated methicillin-resistant Staphylococcus aureus: recent clonal expansion and diversification, Proc. Natl. Acad.Sci. U S A, (105),pp. 1327-1332, 2008.

[3] F.D. Lowy, Antimicrobial resistance: the example of Staphylococcus aureus, J. Clin. Inves., (111),pp.12651273, 2003.

[4] G.R. Golding, L. Bryden, P.N. Levett, R.R. Mc Donald, A. Wong, J. Wylie, R. G. Morag, S. Tyler, V.G. Domselaar, E.S. Andrew, G. Denise, Livestockassociated methicillin-resistant Staphylococcus aureus sequence type 398 in humans, Canada, Emerg. Infect. Dis., (16),pp. 587-594, 2010.

[5] P. Martres, M. Thibault, F. Lemann, Surveillance of multidrug-resistant bacteria: Significant decrease in the rate and incidence of methicillin-resistant Staphylococcus aureus (MRSA) in a general hospital between 1999 -2001, Pathol. Biol.,(51), pp. 474-478, 2003.

[6] M.Gould, The clinical significance of methicillinresistant Staphylococcus aureus, J.Hosp. Infect., (61),pp. 277-282, 2005.

[7] Montesinos, E. Saldo, T. Delgado, T. Cuervo and A. Sierra, Epidemiology genotyping of methicillin-resistant Staphylococcus aureus by Pulsed-Field Gel Electrophoresis at a University Hospital and Comparison with Antibiotyping and Protein A and Coagulase Gene Polymorphisms, J. Clin. Microbiol., (40), pp. 2119-25, 2002.

[8] R.J. Gorwitz, D. Kruszon-Moran, S.K. Mc Allister, G. Mc Quillan, L.K. Mc Dougal, G.E. Fosheim, B.J.Jensen, G. Killgore, F.C. Tenover, M.J. Kuehnert, Changes in the prevalence of nasal colonization with Staphylococcus 
aureus in the United States, 2001-2004. J. Infect. Dis., (197), pp.1226-1234, 2008.

[9] E. Klein, D.L Smith, R. Laxminarayan, Hospitalizations and deaths caused by methicillin-resistant Staphylococcus aureus, United States, 1999-2005, Emerg. Infect. Dis., (13), pp. 1840-1846, 2007.

[10] R. Moyen, G. Ahombo, E. Nguimbi, N.E. Ontsira, R.F. Niama, C.G. Yala, D. Louembe, Activity of beta-lactam antibiotics and production of beta-lactamases in bacteria isolated from wound infections in Brazzaville, Congo. African Journal of Microbiology Research, 8 (23), pp. 2290-2294, 2014.

[11] R. Moyen, E. Nguimbi, G. Ahombo, N.E. Ontsira, G. C.Yala, Obengui, S. C. Kobawila, D. Louembe, Comparative Study to Amino Glycoside Antibiotics Resistance of Staphylococcal Strains Isolated from Wounds at Brazzaville, ISSN (Online), pp. 2319-7064, 2013.

[12] B. Durmaz, R. Durmaz, K. Sahin, Methicillin-resistance among Turkish isolates of Staphylococcus aureus strains from nosocomial and community infections and their resistance patterns using various antimicrobial agents, J. Hosp. Infect. 37 (4), pp. 325-329, 1997)

[13] G. Prats, B. Mirelis, T. Llovet, C. Munoz, E. Miro, F. Navarro, Antibiotic resistance trends in enteropathogenic bacteria isolated in 1985-1987 and 1995-1998 in Barcelona, Antimicrob Agents Chemother, (44), pp. 1140-1145, 2000.

[14] G. Carret, J.D. Cavallo, H. Chardon, C. Chidiac, P. Choutet, P. Courvallin,H. Dabernat, H. Drugeon, L. Dubreuil, F. Golstein, V. Jarlier, R. Leclercq, M.H Nicolas I-Chanoine, A. Philippon, C. Quentin, B. Rouveix, J. Sirot, C.J. Soussy, Communiqué of the antibiogram committee of the French Microbiology Society, 47p, 2001.

[15] H.S. Lim, H.Lee, K.H. Roh, J.H. Yum, D.Yong, K. Lee,Y. Chong, Prevalence of inducible clindamycin resistance in staphylococcal isolates at Korean tertiary care hospital, Yonsei Med. J.,47, pp.480-4,2006.

[16] G. Fahimeh, H. Ghajavand, R. Havaei, J.S. Mohammad, F. Khademi, L. Heydari, M. Shahin, S. A. Havaei, Distribution of erm genes among Staphylococcus aureus isolates with inducible resistance to clindamycin in Isfahan, Iran, Adv. Biomed Res., (5), pp 62,2016.

[17] J. Sekiguchi, T. Fujino, H. Konosaki, H. Nishimura, A. Kawana, K. Kudo,T. Kondo, Y.Yazaki.,T. Kuratsuji, H. Yoshikura, T.Kirikae. Prevalence of erythromycintetracycline, and aminoglycoside-resistance genes in methicillin-resistant Staphylococcus aureus in hospitals in Tokyo and Kumamoto, Japan, J. Infect. Dis.,(57), pp.74 -77, 2004.

[18] J.W. Decousser, P. Pina, C. Delalande, Frequency of isolation and antimicrobial susceptibility of bacterial pathogens from patients with bloodstream infections, J. Antimicrob Chemother, (51), pp. 1213-22, 2003.

[19] H.Portier, M. Armengaud, G.Becq, Treatment with cefotaxime-fosfomycin combination of meningitis in adults with Staphylococci or enterobacteria, Med. Press, (16), pp. 2161-6, 1987.

[20] H Drugeon, B-lactams and Staphylococci, In P. Courvelin, R. Leclercq, E.Bingen Antibiotic susceptibility, ESKA 12 (Eds), Paris, pp. 117-24, 2006.
[21] A.D.C. Fluid, M.R.Screw, F.Schmitz, Molecular detection of antimicrobial resistance, Clin. Microbiol. Rev., (14), pp. 836-871, 2001.

[22] M.L. Dia, K. Diongue, A. Diop, R .Ka, M.A. Sonko, R. Diagne, A.I. Sow, M.F. Cisse, Mechanisms of $\beta$-lactam resistance in isolated Staphylococcus aureus strains at Dakar (senegal) hospital, CAMES HEALTH,(2), pp. 912, 2014.

[23] X. Bertrand, A. Mueller, M. Thowverez, D. Talon, Back to antibiotic sensitivity of methicillin-resistant Staphylococcus aureus strains (MRSA): relationship between genotype and antibiotic, Path. Biol.,(52), pp.480-5, 2004.

[24] C. K. Akoua, N. Guessennd, V. Gbonon, H. K.Faye, M. Dosso, Methicillin resistance of isolated Staphylococcus aureus in Abidjan (1998-2001): a new problem in hospitals. Med. Mal. Infect.,(34), pp.132-6, 2004.

[25] R. Leclercq, Resistance of Staphylococci to antibiotics, Ann. Fr. Anesth. Réanim.,(21), pp. 375-383, 2002.

[26] K. Kayode. Ojo, J.S. Megan, C.C. Ulep, S. C. Natasha, J. Zittle, L. Henrique, M. Bernardo, J. Leitao, M.C. Roberts, Effrux msr (A) Characterized Gene in Streptococcus, Enterococcus, Corynebacterium, and Pseudomonas Isolates, Antimicrob Agents Chemother, 50 (3), pp.1089-1091, 2006.

[27] K. Chaieb, A. Touati., M.S. Abbassi, B.A. Hassen, K. Mahdouani, A. Bakhrouf. DNA fingerprinting of a multiresistant coagulase-negative Staphylococci isolated from biomaterials in dialysis service, Arch. Med. Res.,(3), pp. 953-960, 2006.

[28] T. Zmantar, K. Chaied, B.B. Abdallah, B.A.N. Kahla, B.A. Hassenc, K. Mahdouani, A. Bakhrouf. Multiplex PCR detection of antibiotic resistance genes in strains of Staphylococcus aureus isolated from ear infections. Folia Microbial., 53 (4), pp. 357-362, 2008.

[29] O. Raimundo, H. Heussler, J. B. Bruhn, S. Suntrarachun, N. Kelly, M. A. Deighton, S. M. Garland, Molecular epidemiology of coagulase-negative Staphylococcal bacteremia in a newborn intensive care unit. J. Hosp. Infect., (51), pp. 33- 42, 2002.

[30] M. De Guisti, L. Pacifico, D.Tufi, A. Panero, A. Boccia, C. Chiesa, Phenotypic detection of nosocomial mecA positive coagulase negative Staphylococci from neonates, J. Antimicrob. Chemother, (44),pp. 351-358, 1999.

[31] N. Ardic, M. Ozyurt, B. Sareyyupoglu, T. Haznedaroglu, Investigation of erythromycin and tetracycline resistance in methicillin-resistant Staphylococci, Int. J. Antimicrob Agents, (26), pp. 213-218, 2005.

[32] S. Shoja, M. Nahaei, Detection of inducible clindamycin resistance in Staphylococcus aureus and Staphylococcus epidermidis by using D-test, Pharma Sci., (15), pp. 1-8, 2009.

[33] M.A. Pfaller, R.N. Jones, G.V. Doern, H.S. Sader, K.C. Kugler, M.L. Beach, Survey of bloodstream infections attributable to Gram-positive cocci: frequency of occurrence and antimicrobial susceptibility of isolates collected in 1997 in the United States, Canada, and Latin America from the SENTRY Antimicrobial Surveillance Program. Sentry Participants Group, Diagn. Microbiol. Infect. Dis.,(33), pp. 283-297,1999.

[34] S.A. Marshall, W.W. Wilke, M.A. Pfaller, R.N. Jones, Staphylococcus aureus and coagulase-negative Staphylococci from bloodstream infections: frequency of 
occurrence, antimicrobial susceptibility, and molecular (mecA) characterization of oxacillin resistance in the SCOPE program, Diagn. Microbiol. Infect. Dis., (30), pp. 205-214,1998.

[35] M.C. Layton,W.J.J. Hierholzer, J.E. Patterson,The evolving epidemiology of methicillin-resistant Staphylococcus aureus at a university hospital, Infect. Contr. Hosp. Epidemiol.,(16), pp. 12-17, 1995.
[36] B.R. Lyon, R. Skurray, Antimicrobial resistance of Staphylococcus aureus: genetic basis. Microbiol. Rev., 51 (1), pp. 88-134, 1987.

[37] T. Zmantar, B. Kouidhi, H. Miladi, A. Bakhrouf, Detection some genes of resistance to macrolides and within disinfecting in the Staphylocoques aureus clinic and coagulase-negative Staphylococcus, BMC Res Notes, (4), pp. 453,2011. 